\title{
Evaluation of Oxidant and Antioxidant Systems in Drought Response of Cowpea Varieties
}

\author{
Maimuna Dalhatu ${ }^{1}$ Sadiya Bichi $^{1} \quad$ Yusuf Yunusa $^{2} \quad$ Abdulmumin Yunusa $^{1}$ \\ Tasiu Abdulmumin $^{1} \quad$ Fiddausi Abdulqadir $^{3} \quad$ Zeenat Saulawa $^{2} \quad$ Balkisu Abdurrahman $^{4}$ \\ Shahida Sarki ${ }^{1} \quad$ Ibrahim Muhammad $^{1}$ \\ 1. Department of Biochemistry, Kano University of science and Technology, Wudil, P.M.B 3244, Kano, Nigeria \\ 2. Department of Biochemistry, Bayero University, Kano, P.M.B 3011 kano Nigeria \\ 3. Department of Biochemistry, Yusuf Maitama Sule University, Kano Nigeria \\ 4. Department of Biochemistry, Federal University, Dutsinma P M B 5001 Katsina, Nigeria.
}

The research is funded by Tertiary Education Trust fund (TETFUND) Nigeria, through Kano University of Science and Technology, Wudil, Kano State, under Institutional Based Research Grant (TETFUND/DESS/UNI/WUDIL/IBR/2018/VOL1).

\section{Abstract}

Plant in their natural environment are exposed to several stresses such as the drought that affect their growth and productivity. Exposure of plant to drought leads to oxidative stresses as a result of increase in ROS, however plant counteract this effect by its antioxidant system. $\mathrm{H}_{2} \mathrm{O}_{2}$, malondialdehyde, membrane stability index, catalase and ascorbate peroxidase activities where evaluated in leaves of two cowpea varieties drought tolerant (Dan'ila) and drought susceptible (TVU 7778) during 2 weeks water deficit and 5days recovery. The result indicates significant increase in the $\mathrm{H}_{2} \mathrm{O}_{2}$, MDA, CAT and APX activities in both varieties during the stress period and significant decrease during recovery in drought tolerant variety compared to the drought susceptible variety. The membrane stability index decreases significantly during stress period in both varieties. Drought tolerant variety has the higher ability to counteract oxidant activity during the drought stress and recover faster than the drought susceptible variety.

Keywords: Drought, antioxidant, cowpea

DOI: $10.7176 / \mathrm{JNSR} / 12-8-03$

Publication date: April $30^{\text {th }} 2021$

\section{Introduction}

Plants are exposed to different kinds of stress which may originate from human or natural causes such as drought. Drought stress severely impacts plant development, growth and fertility. Stress imposed stress on plants commonly accompanied by an increase in the production of reactive oxygen species (ROS) that lead to an imbalance between their production and scavenging. Despite their reactive and thus toxic nature, ROS are also key components of signal transduction pathways that trigger stress responses. Furthermore, ROS are involved in plant developmental processes (Mhamdi and Breusegem, 2018) and plant-microbe interactions (Segal and Wilson, 2018). However, excessive ROS production must be counteracted by the antioxidant system to prevent damage development and cell death. The first response of plants to drought is the closure of stomata in order to minimize water loss due to transpiration. Depletion of the intercellular carbon dioxide $\left(\mathrm{CO}_{2}\right)$ concentration stimulates ribulose-1,5-bisphosphate oxygenation and, thus, photorespiratory hydrogen peroxide $\left(\mathrm{H}_{2} \mathrm{O}_{2}\right)$ production in the peroxisomes by the dismutation of $\mathrm{O}_{2} \bullet^{-}$. Sequence of detoxification steps is often required to avoid the conversion of one reactives pecie to $2^{\text {nd }}$ more harmful one such as the $\mathrm{OH}$ radical Detoxification of $\mathrm{H}_{2} \mathrm{O}_{2}$ to and $\mathrm{O}_{2}$ is achieved primarily by the action of catalase in the peroxisomes and ascorbate peroxides in the chloroplast. Drought also induces lipid peroxidation leading to disruption of cell membrane.

\subsubsection{Materials and methods}

The experiment was conducted between September to October 2018 at a greenhouse of Faculty of Agriculture, Bayero university, Kano (approximate temperature of $35 / 28^{\circ} \mathrm{C}$ (day/night), $50-80 \%$ of relative humidity and 13 h photoperiod recorded with data $\log \left(11^{\circ} 58^{\prime} \mathrm{N}\right.$ and $8^{\circ} 25^{\prime} \mathrm{E} 457 \mathrm{~m}$ above sea level) in the savanna ecological zone of Nigeria. Two beans variety drought tolerant Dan-ila and Drought susceptible TVU 7778 were collected from International Institute of Tropical agriculture. Before sowing, seeds were surface sterilized with $2.5 \%$ sodium hypochlorite for $20 \mathrm{~min}$, then were washed with sterile deionized water. The experimental pots $12 \mathrm{~cm} \times 8 \mathrm{~cm} 5$ liter capacity were used and arranged in a simple randomized design with six replicates per treatment per variety. Five seeds were sown per pot at the depth of $3 \mathrm{~cm}$ which were later thinned to 3 seedling per pot at 2 weeks after sowing. Spacing of $20 \mathrm{~cm}$ inter row and $10 \mathrm{~cm}$ intra row was used in the pots arrangement. Each pot was irrigated to field capacity once daily with borehole water having $7.5 \mathrm{pH}, 1.2 \mathrm{dsm}^{-1}$ electrical conductivity (EC) and $1200 \mathrm{mg} \mathrm{L}^{-1}$ total soluble salts (TSS) until the start of the stress treatments. Water deficit was introduced at 5 weeks after sowing by totally withholding irrigation for a period of 2 weeks for the stressed group. Irrigation was resumed for 5 days to assess level of recovery. Sample of the plant leaves were collected at 
$0,5,10,15$ days drought and 5 days after re-watering for biochemical analyses.

Fully expanded leaves were collected in the morning and then washed with deionized water; the adhering water was removed with a paper towel. The leaf samples were immediately frozen in liquid nitrogen to prevent proteolytic activity and taken to the Laboratory for analysis.

\subsubsection{Antioxidant enzymes Extraction}

Enzyme extract for catalase (CAT) was prepared by weighing ( $1 \mathrm{~g})$ followed by grinding with $5 \mathrm{ml}$ of cold extraction buffer $(0.1 \mathrm{M}$ phosphate buffer, $\mathrm{pH} 7.8$, containing $0.5 \mathrm{mM}$ EDTA, and 2\% (w/v) polyvinylpyrrolidone (PVP), filtrate was centrifuged for $20 \mathrm{~min}$ at $10,000 \mathrm{~g}$ and the supernatant was used as enzyme extract. All steps in the preparation of the enzyme extract were carried out at $4{ }^{\circ} \mathrm{C}$. For measuring ascorbate peroxidase (APX) activity, the leaves was separately grounded in homogenizing medium containing $2.0 \mathrm{mM}$ AsA in addition to the other previous ingredients.

\subsubsection{Ascorbate peroxidase activity}

Ascorbate Peroxidase (APX) activity was assayed following methods adopted by Nakano and Asada (1981). The reaction mixture $(3 \mathrm{ml})$ contained $50 \mathrm{mM}$ potassium phosphate buffer $(\mathrm{pH} 7.0), 0.5 \mathrm{mM}$ ascorbic acid, $0.1 \mathrm{mM}$ EDTA, and $1.5 \mathrm{mM} \mathrm{H} \mathrm{O}_{2}$ and $0.1 \mathrm{ml}$ enzyme extract. The reaction was started with the addition of $\mathrm{H}_{2} \mathrm{O}_{2}$. Absorbance change was measured at $290 \mathrm{~nm}$ every $30 \mathrm{~s}$ for $5 \min \left(\mathcal{E}=2.8 \mathrm{mM} \mathrm{cm}^{-1}\right)$ using spectrophotometer. APX activity was expressed as Units per gram fresh.

\subsubsection{Catalase activity}

Catalase activity (CAT) was determined following the reaction of the extract in the presence of $50 \mathrm{mM}$ potassium phosphate buffer ( $\mathrm{pH}$ 7.0) containing $12.5 \mathrm{~mm} \mathrm{H}_{2} \mathrm{O}_{2}$ and $50 \mu$ lenzyme extract and water was made up to $3.0 \mathrm{ml}$. The reaction took place at $25^{\circ} \mathrm{C}$, by adding $\mathrm{H}_{2} \mathrm{O}_{2}$ with absorbance monitored at $240 \mathrm{~nm}$ for $60 \mathrm{~s} \mathrm{(Aebi,}$ 1984). CAT specific activity was expressed as Units per gram fresh weight calculated using the molar absorptivity of $43.6 \mathrm{mM}^{-1} \mathrm{~cm}^{-1}$ for $\mathrm{H}_{2} \mathrm{O}_{2}$ at $240 \mathrm{~nm}$.

\subsubsection{Hydrogen peroxide}

To determine the level of hydrogen peroxide, $0.3 \mathrm{~g}$ of leaf tissue was homogenized with $5 \mathrm{~mL} 0.1 \%$ trichloroacetic acid (TCA). The homogenate was centrifuged at $10,000 \times \mathrm{g}$ for 5 minutes. Then, $0.25 \mathrm{~mL}$ of the supernatant was mixed with $0.25 \mathrm{~mL}$ of $100 \mathrm{mM} \mathrm{K}$-phosphate buffer and $0.5 \mathrm{~mL}$ of $1 \mathrm{M} \mathrm{KI}$. The absorbance was measured at $390 \mathrm{~nm}$ with a spectrophotometer. Hydrogen peroxide level was calculated using a standard curve prepared with known $\mathrm{H}_{2} \mathrm{O}_{2}$ concentrations (Alexieva et al. 2001).

\subsubsection{Lipid peroxidation}

Lipid peroxidation was measured by determining the malondialdehyde (MDA) content in the leaves according to the method of Dhindsa et al. (1981). $5 \mathrm{~mL}$ of trichloroacetic acid (0.1\% TCA) was added to $0.3 \mathrm{~g}$ of leaf tissues and homogenized completely. The homogenated samples were centrifuged at $10,000 \times \mathrm{g}$ for $5 \mathrm{~min}$. at $4{ }^{\circ} \mathrm{C}$. The supernatant $(0.3 \mathrm{ml})$ was mixed with $1.2 \mathrm{ml}$ of $0.5 \%$ thiobarbituric acid (TBA) prepared in $20 \%$ TCA, and incubated at $95^{\circ} \mathrm{C}$ for $30 \mathrm{~min}$. The reaction was stopped by putting the sample in an ice bath for 5 min.; samples were centrifuged at $10,000 \times \mathrm{g}$ for $10 \mathrm{~min}$. at $25^{\circ} \mathrm{C}$. The absorbance of the supernatant was read at $532 \mathrm{~nm}$ using spectrophotometer. After deducting the non-specific absorbance at $600 \mathrm{~nm}$, the extinction coefficient of 155 $\mathrm{mM}^{-1} \mathrm{~cm}^{-1}$ was used to calculate the MDA concentration.

\subsubsection{Membrane stability index and membrane injury}

Membrane stability index and membrane injury. The membrane stability index (MSI) was measured by using a conductivity meter following the method of Khanna-Chopra and Selote, (2007). Leaf samples of $200 \mathrm{mg}$ were thoroughly washed in double distilled water and placed in two separate $10 \mathrm{~mL}$ tubes of distilled water. One tube was heated for $30 \mathrm{~min}$ at $40{ }^{\circ} \mathrm{C}$ in a water bath and electrical conductivity was measured $(\mathrm{C} 1)$. The second set was boiled for $10 \mathrm{~min}$ at $100{ }^{\circ} \mathrm{C}$ in a boiling water bath and electrical conductivity was measured (C2). The MSI was estimated by the equation given below:

$$
\mathrm{MSI}=\left[1-\frac{(\mathrm{C} 1)}{\mathrm{C} 2}\right]^{*} 100
$$

Membrane injury (MI) was estimated as ratio of MSI of drought-stressed plants and MSI of control plants as given by Dhanda et al.2004

M I $(\%)=[1-(\underline{M S I d})]^{*} 100$

MSIC

\subsection{Statistical analysis}

Comparison between groups were performed using Student's paired t-test. Data was expressed as mean \pm Standard deviation. Significant difference was placed at $\mathrm{p}<0.05$.

\subsection{Results}

1.3.1 Changes in $\mathrm{H}_{2} \mathrm{O}_{2}$ and $M D A$ contents.

Drought stress caused an increase in $\mathrm{H}_{2} \mathrm{O}_{2}$ and MDA concentrations (Figure 1and 2) and a decrease in 
Membrane stability index (Figure 3) in drought susceptible variety (TVU 7778) compared to drought tolerant variety (Danila).However, the drought tolerant variety showed a faster recovery upon re-watering than the drought susceptible variety.

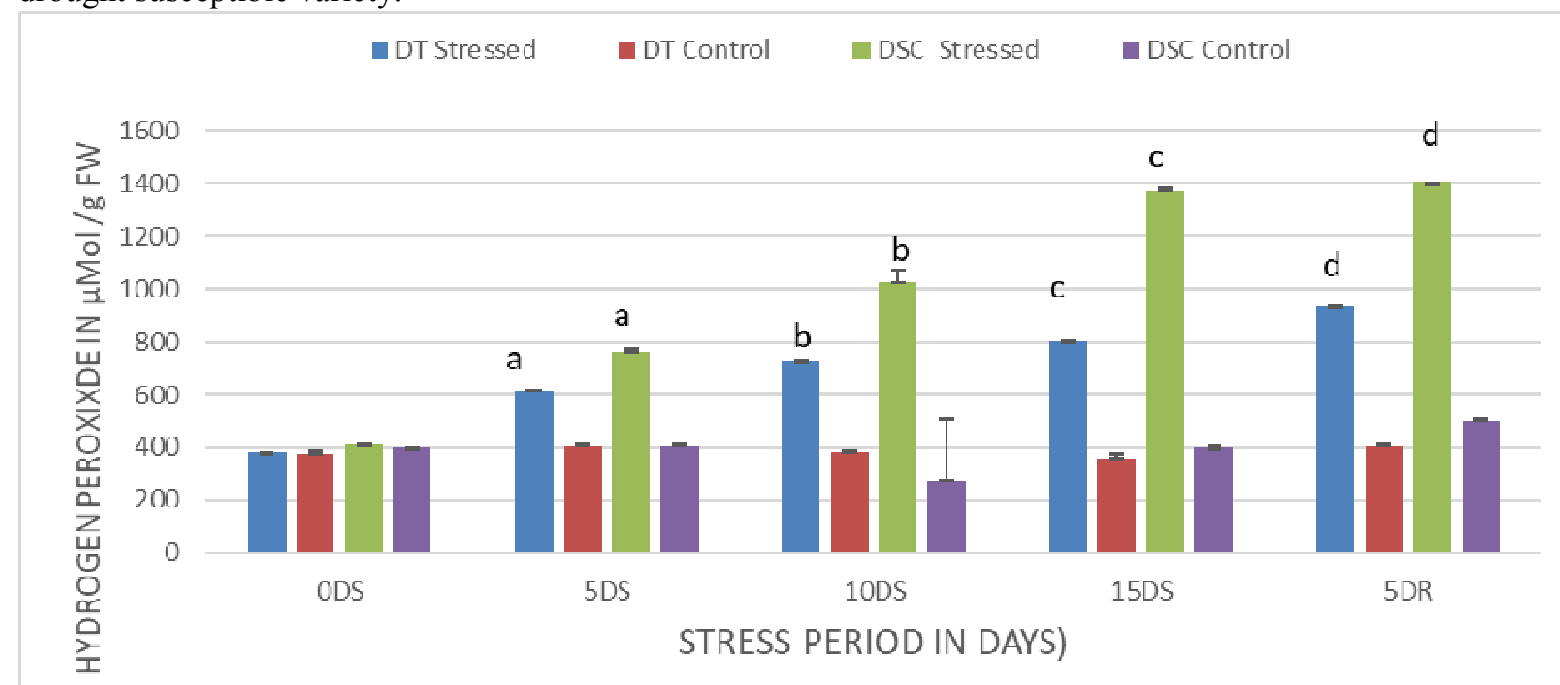

Figure 1: Effect of drought stress on hydrogen peroxide concentration in drought tolerant and drought susceptible cowpea varieties. Values within the same stress period bearing same alphabet are significant at $\mathrm{P}<0.05, \mathrm{DSC}=$ drought susceptible, $\mathrm{DT}=$ drought tolerant, $\mathrm{DS}=$ days of stress, $\mathrm{DR}=$ days of rewatering.

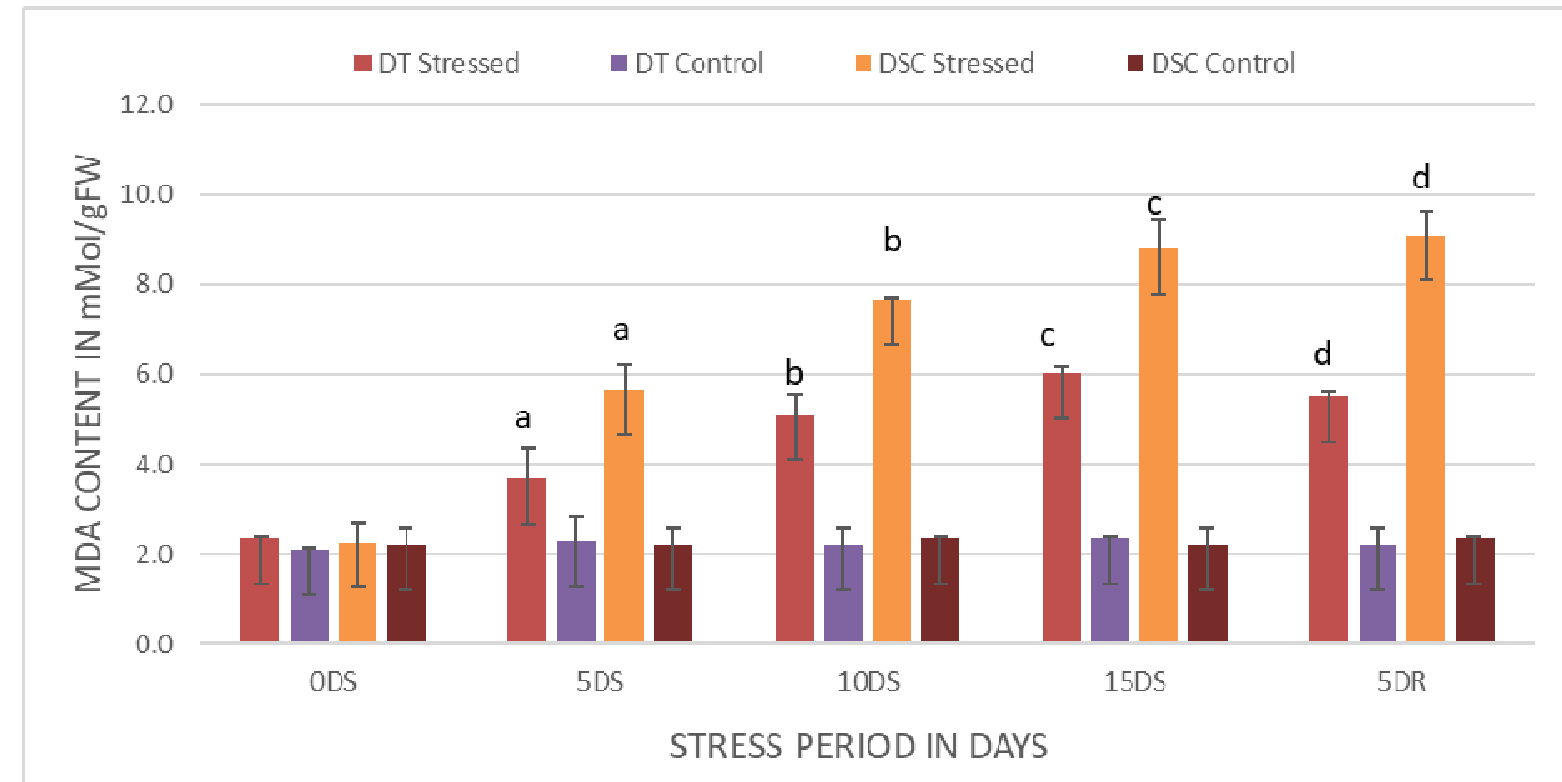

Figure 2: Effect of drought stress on malondialdehyde content in drought tolerant and drought susceptible cowpea varieties. Values within the same stress period bearing same alphabet are significant at $p<0.05$. $\mathrm{MDA}=$ malondialdehyde, $\mathrm{DSC}=$ drought susceptible, $\mathrm{DT}=$ drought tolerant, $\mathrm{DS}=$ days of stress, $\mathrm{DR}=\mathrm{days}$ of rewatering. 


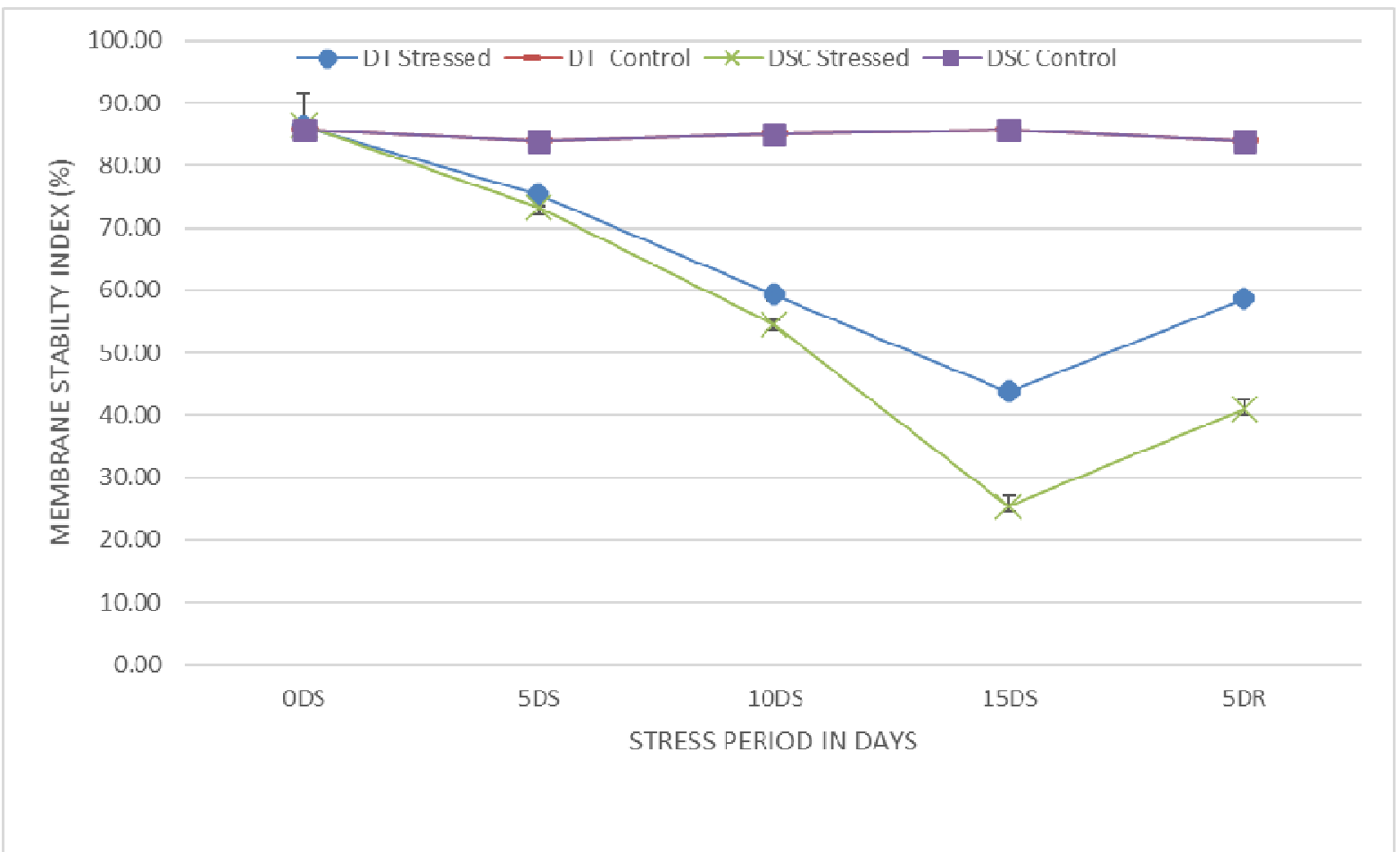

Figure 3: Effect of drought stress on membrane stability index in drought tolerant and drought susceptible cowpea varieties. $\mathrm{DSC}=$ drought susceptible, $\mathrm{DT}=$ drought tolerant, $\mathrm{DS}=$ days of stress, $\mathrm{DR}=$ days of rewatering.

\subsubsection{Changes in enzymatic antioxidant activities.}

During drought stress, the enzymatic activities of CAT and APX increased (Fig. 4 and 5). A rapid increase in the activities of CAT and APX was observed, which reached a maximum at 15DS .Overall antioxidant enzyme activities were higher in drought tolerant than drought susceptible with significant difference $(P \leq 0.05)$ between the stress period. After re-watering, CAT and APX activities decreased significantly in drought tolerant plants as compared to drought susceptible plants. By comparison, in Drought tolerant plants, enzyme activities recovered to the level of control plants on 10DS whereas in drought susceptible the decrease is insignificant $(\mathrm{P}>0.05)$.

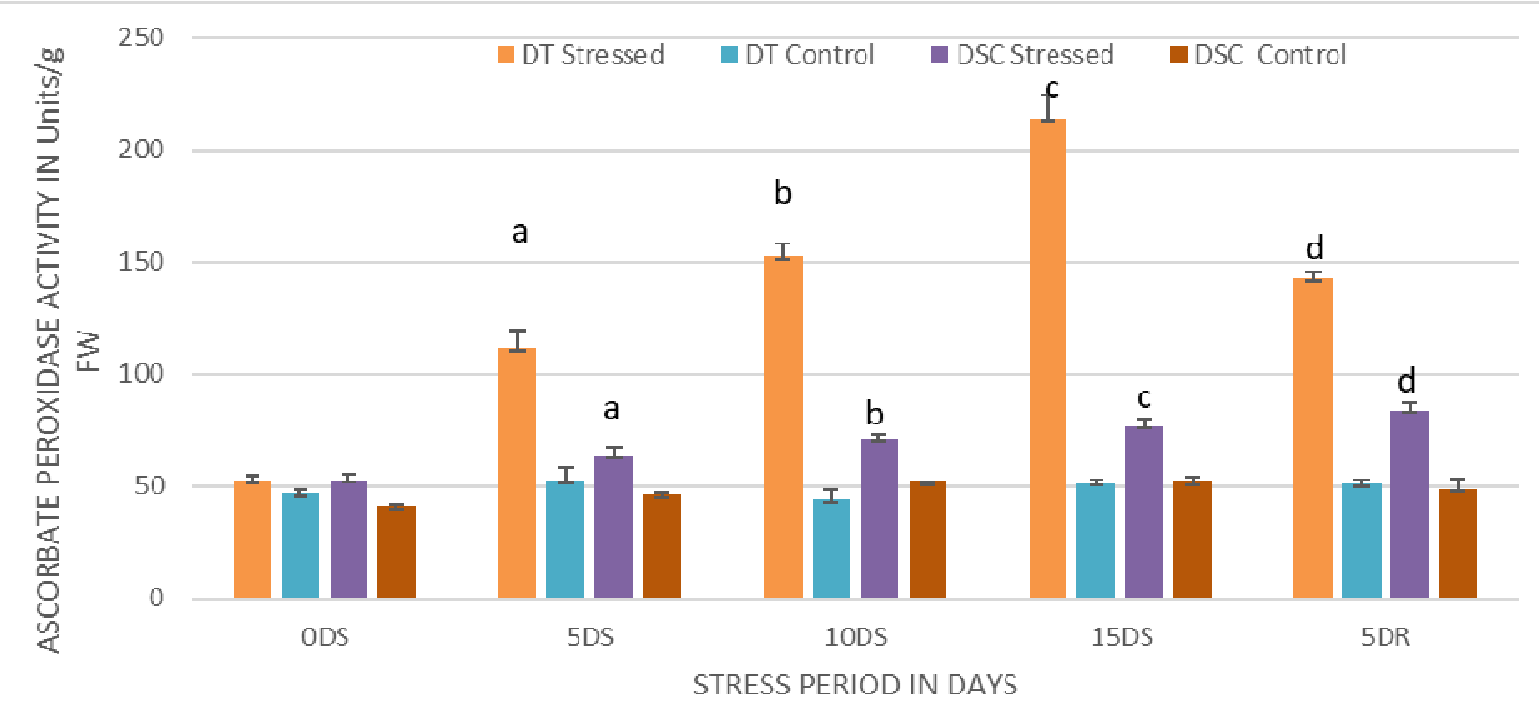

Figure 4: Effect of drought stress on ascorbate peroxidase activity in drought tolerant and drought susceptible cowpea varieties. Values within the same stress period bearing same alphabet are significant at $\mathrm{p}<0.05$. $\mathrm{DSC}=$ drought susceptible, $\mathrm{DT}=$ drought tolerant, $\mathrm{DS}=$ days of stress, $\mathrm{DR}=$ days of rewatering. 


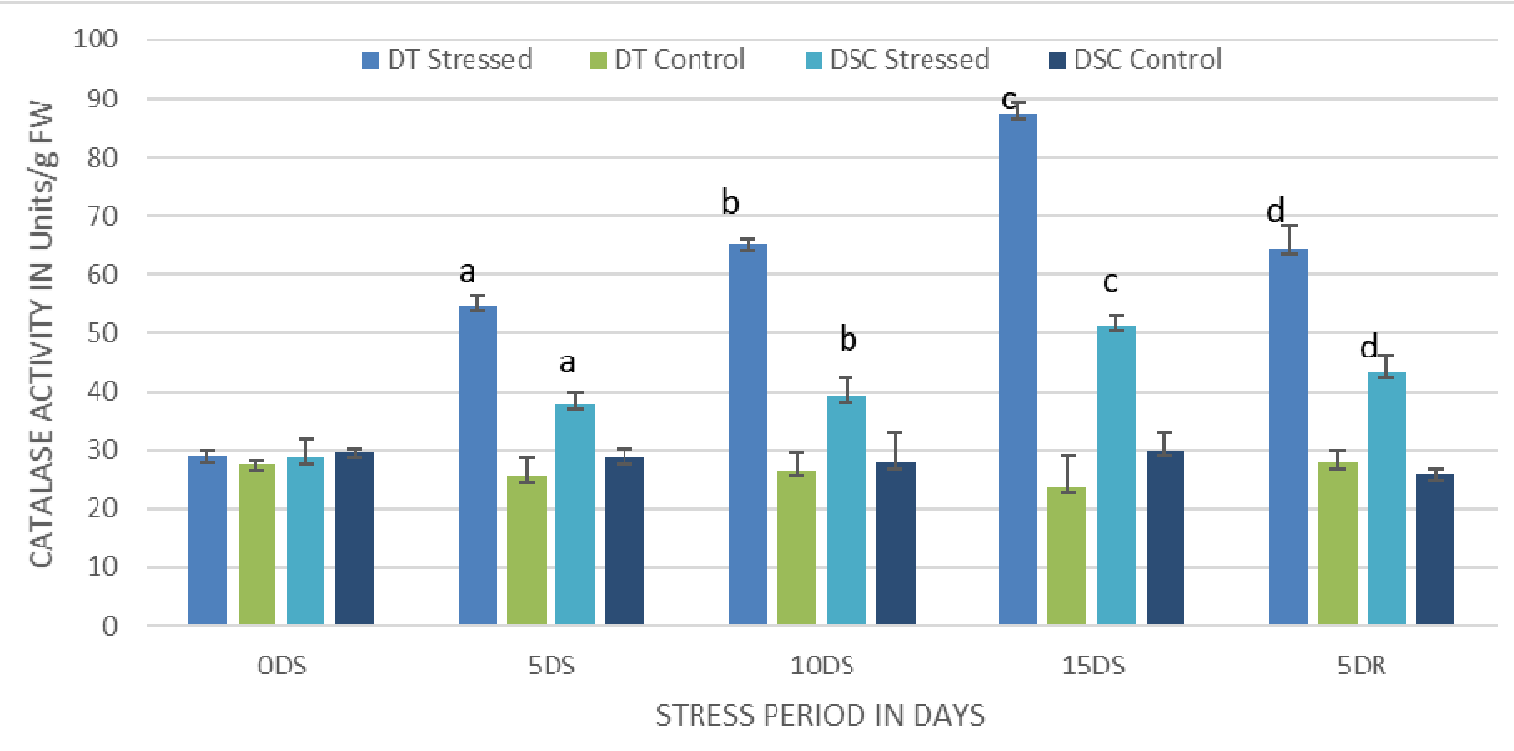

Figure 5: effect of drought stress on catalase activity in drought tolerant and drought susceptible cowpea varieties. Values within the same stress period bearing same alphabet are significant at $\mathrm{p}<0.05$. DSC $=$ drought susceptible, $\mathrm{DT}=$ drought tolerant, $\mathrm{DS}=$ days of stress, $\mathrm{DR}=$ days of rewatering.

\subsection{Discussion}

Reactive oxygen species such as hydrogen peroxide are constantly being generated at normal metabolic levels. However they are unable to cause damage as they are being scavenged by different antioxidant mechanisms (Foyer and Noctor, 2000).The balance between ROS generation and ROS scavenging is disturbed by different types of stress factors like salinity, drought and etc. Drought stress stimulates the production of ROS (Lui and Huang ,2000) because of stomatal aperture closure and low availability of $\mathrm{CO}_{2}$ and its fixation Ribulose 1,5bisphophate oxygenation is favoured and thus photorespiration is enhanced which account for more than $70 \%$ of the $\mathrm{H}_{2} \mathrm{O}_{2}$ produced as result of drought stress (Noctor et al, 2002). There was a significant increase in the amount of $\mathrm{H}_{2} \mathrm{O}_{2}(\mathrm{P}<0.05)$ as drought stress is increased in the two varieties of cowpea but Drought tolerant specie showed a speedy recovery during rewarering than the drought susceptible, however the unstressed plants of both varieties showed similar index. Increased in lipid peroxidation shown by significant rise in MDA and reduction in membrane stability was also seen during drought stress period which is in line with the findings of (Zlatev and Lidon 2012) that says increased ROS cause membrane injuries that translate to decrease in membrane stability. The result thus indicates the degree of membrane damage was higher due to water stress ( Chowdhury et al 2017.

Drought caused a distinct increase in the CAT and APX (Fig. 3 and 4) activities with Danila displaying some signalling molecules, such as oxidative molecules, may cause an increase in the antioxidant capacity of cell (Leila et al 2017). To alleviate cellular injury, stressed plants produce antioxidant enzymes (Zlatev and Lidon 2012). In leaf tissue $\mathrm{CAT}$ is localized in peroxisomes to scavenge $\mathrm{H}_{2} \mathrm{O}_{2}$ produced by glycolate oxidase in $\mathrm{C} 2$ photorespiration. The peroxisome is linked to the photosynthetic metabolism via photorespiration process and according to some findings may make part of oxidative tolerance (Luis and Eduardo, 2016). APX has an important role in the AsA-GHs cycle under stress activity of this enzyme is usually considered as an indicator of plant tolerance against the stress (Osman, 2015). The AsA-GSH cycle is known to be responsible for $\mathrm{H}_{2} \mathrm{O}_{2}$ scavenging in chloroplast (Asada,1992). As a consequence of CAT and APX's role in scavenging $\mathrm{H}_{2} \mathrm{O}_{2}$, an increase in CAT and APX activities can be regarded as a defence mechanism of the plant against the reinforcement of oxidative processes.

\section{Conclusion}

The cowpea plants subjected to drought had higher MDA, $\mathrm{H}_{2} \mathrm{O}_{2}$ and MSI in drought tolerant compared to the drought susceptible and control. CAT and APX activities involving enzymatic antioxidants were increased due to the stress caused by drought. Based on the results of this study, it is clear that water-deficit conditions affects the oxidant and antioxidant system of cowpea plant with the drought tolerant variety showing remarkable positive response than the drought susceptible suggesting that enzymatic antioxidant system plays a vital role in drought tolerant of cowpea plant. 


\section{References}

Aebi, H. (1984) Catalase in vitro. In: Methods in Enzymology, vol. 105. Academic Press, pp. 121-126.

Alexieva V., Sergiev I., Mapelli S., Karanov E. (2001). The effect of drought and ultraviolet radiation on growth and stress markers in pea and wheat Plant. Cell Environ. 24(12): 1337-1344.

Khanna-Chopra, R. \& Selote, D. S. (2007) Acclimation to drought stress generates oxidative stress tolerance in drought-resistant than -susceptible wheat cultivar under field conditions. Environ. Exp. Bot. 60(35):276-283

Dhindsa R.S., Plumb-Dhindsa P., Thorpe T.A. (1981). Leaf senescence: correlated with increased levels of membrane permeability and lipid peroxidation, and decreased levels of superoxide dismutase and catalase. $J$. Exp. Bot. 32(1): 93-101.

Nakano, Y., Asada, K. (1981). Hydrogen peroxide is scavenged by ascorbate-specific peroxidase in spinach chloroplasts. Plant Cell Physiol. 22 (5), 867-880

Segal L.M., Wilson R.A. (2018) Reactive oxygen species metabolism and plant-fungal interactions. Fungal Genet. Biol. 110:1-9.

Mhamdi A., Van Breusegem F. (2018) Reactive oxygen species in plant development. Development. 145 (15).

Liu X., Huang B. (2000). Heat stress injury in relation to membrane lipid peroxidation in creeping bentgrass. Crop Sci. 40(2): 503-510.

Hoekstra F.A., Golovina E.A., Buitink J. (2001). Mechanisms of plant desiccation tolerance. Trends Plant Sci. 6(9): 431-438.

Zlatev Z., Lidon F.C. (2012). An overview on drought induced changes in plant growth, water relations and photosynthesis. Emir. J. Food Agric. 24(1): 57-72.

Leila, K., Nasser, G., and Taimoor J. (2017). Morphological and physiological responses of grapevine (Vitis vinifera L.) to drought stress and dust pollution. Folia Hort. 29(2):231-240

Luis A.deo Rio and Eduardo Lopez (2016) ROS generation in peroxisomes and its role in cell signaling. Plant and Cell Physiology 57(7):1364-1376

Osman,H.S (2015)Enhancing antioxidant yield relationship of pea plant under drought at different gr wth stages by exogenous sapplied glycine betain and proline. Annals of Agricultural Science 60(2) 389-402

Rafael Perl-Treves and Avihai Perl oxidative stress in plants pg 8-9(1 ${ }^{\text {st }}$ ed.) CRC press. 